\title{
FENOMENA BULLYING ANTAR SISWA
}

\author{
Heryana Mardika Isman \\ UNTAN, Pontianak, Indonesia \\ E-mail:fromheavens17@yahoo.com
}

\begin{abstract}
Abstrak: Penelitian ini bertujuan untuk mengetahui bentuk-bentuk bullying, faktor penyebab bullying dan upaya SMA Panca Bhakti Pontianak dalam menanggulangi masalah bullying antar siswa. Metode yang digunakan adalah pendekatan kualitatif. Hasil penelitian menunjukkan bahwa bentuk bullying yang terjadi adalah bullying fisik berbentuk pukulan, menghilangkan pulpen teman lain dan pemalakan, selain itu bullying verbal berbentuk sorakan dan pemanggilan nama khusus untuk siswa lain. Faktor penyebabnya adalah faktor keluarga, teman sebaya dan lingkungan sosial. Dan usaha SMA Panca Bhakti Pontianak dalam menanggulangi bullying antar siswa adalah menerapkan pengendalian sosial berupa preventif, dengan mengadakan kegiatan pengembangan diri siswa dan sosialisasi tata tertib. Sedangkan pengendalian sosial represif dengan memberikan peneguran secara lisan dan membuat pernyataan untuk memperbaiki diri. Selain itu pengendalian sosial kuratif dilakukan teguran secara tertulis berupa pemanggilan orang tua, apabila si bully masih saja melakukan bullying maka akan di skors 3 hari, 7 hari dan bahkan bisa di kembalikan kepada orang tua atau keluarkan dari SMA Panca Bhakti Pontianak, dengan terlebih dahulu memperhatikan pertimbangan-pertimbangan yang memberatkan dan meringankan.
\end{abstract}

Kata Kunci : Bullying, Siswa, Pengendalian Sosial.

\section{PENDAHULUAN}

Sekolah merupakan institusi yang menjadi ujung tombak keberhasilan atau kegagalan pencapaian tujuan pendidikan nasional. Sesuai dengan UU. No.20 tahun 2003 Pasal 3, pendidikan bertujuan untuk mengembangkan potensi peserta didik sehingga menjadi manusia yang beriman dan bertakwa, berakhlak mulia, sehat, berilmu, cakap, kreatif, mandiri dan menjadi warga negara yang bertanggungjawab. Untuk mewujudkan hal tersebut, dalam pelaksanaannya tentu saja banyak faktor yang mempengaruhi kelancaran program tersebut.Masalah yang paling sering terjadi yaitu seperti senior menghukum junior, memukul teman sebaya, menendang, menggunakan nama panggilan yang kurang baik, mengejek, menghina serta menggoda atau dengan cemoohan seksual, dan masih banyak masalah-masalah serupa.Semuanya itu termasuk dalam kategori tindakan bullyingserta krisis moral.

Menurut Wiyani (2014: 12) bullying adalah "penggeretak, orang yang menganggu orang yang lemah".Selain itu menurut Eko (2011: 342) perilaku agresif seseorang atau sekelompok orang yang dilakukan secara berulang-ulang terhadap orang atau sekelompok orang lain yang lebih lemah untuk menyakiti korban secara fisik maupun mental.Penyebab dari praktik-praktik perilaku bullying tersebut diatas juga beragam, seperti yang dikatakan oleh Priyatna (2010: 5-7) Tidak ada penyebab tunggal dari bullying. Banyak faktor yang terlibat dalam hal ini, baik itu faktor pribadi anak itu sendiri, keluarga, lingkungan, bahkan sekolah, semua turut mengambil peran.
Semua faktor tersebut, baik yang bersifat individu maupun kolektif, memberi kontribusi kepada seorang anak sehingga akhirnya dia melakukan tindakan bullying.

Di Indonesia kasus bullying banyak terjadi diberbagai tempat, berdasarkan laporan Telepon Sahabat Anak (TEPSA) kepada Kementerian Sosial Republik Indonesia, hingga Juli 2017 terdapat 117 kasus bullying terjadi pada pada anak sekolah (Indrawan, 2017). Berdasarkan survei yang dilakukan Kementerian Sosial Republik Indonesia pada anak usia 12 hingga 17 tahun, setidaknya $84 \%$ diantaranya pernah mengalami kasus bullying di sekolah (Saputra, 2017). Belum lagi banyaknya pemberitaan tentang tindak kekerasan yang ada di media cetak maupun layar televisi, seperti kasus yang pada saat ini sedang hangat menjadi pembicaraan yakni kasus perundungan Audrey, seorang gadis 14 tahun yang masih duduk di bangku SMP di keroyok oleh 3 orang anak SMA, masalah tersebut disebabkan oleh masalah percintaan yang menggeluti mereka, masalah ini terjadi di Kota Pontianak pada bulan April 2019.

Berdasarkan data di atas, bahwa kasus bullying antar siswa hingga kini masih tergolong tinggi. Sekolah yang seharusnya menjadi tempat bagi anak untuk menimba ilmu dan membantu membentuk karakter pribadi yang positif ternyata malah menjadi tempat tumbuhnya praktik-praktik bullying. SMA Panca Bhakti Pontianak merupakan salah satu sekolah swasta yang berada di Kota Pontianak. Tercatat hingga tahun ajaran baru 2019/2020 saat ini menampung 148 siswa dari 5 ruang kelas. Dalam sebuah kelas memuat 23-33 siswa, dan sekolah ini memiliki akreditasi A. 
Namun, dengan adanya akreditasi tersebut tidak dapat menjamin bahwa siswa yang bersekolah di SMA Panca Bhakti ini memiliki kepribadian yang baik, disiplin dan mentaati aturan. Bahkan beberapa masalah pernah terjadi di sekolah ini dalam kurun waktu 3 tahun terakhir. Pada tahun 2017 tercatat 13 kali masalah bullying yang terjadi dengan jenis bullying fisik dan verbal. Di tahun 2018 menjadi tahun yang memprihatinkan, mengingat jumlah bullying yang terjadi di tahun ini cukup tinggi yakni 20 kali. Sedangkan bullying yang tercatat pada tahun 2019 hingga bulan Juli ada 17 kali, total keseluruhan masalah tersebut 50 kali.

Lokasi penelitian yang diambil adalah SMA Panca Bhakti Pontianak, sekolah ini merupakan salah satu sekolah menengah atas swasta yang ada di Kota Pontianak. Berangkat dari latar belakang tersebut diatas, maka peneliti tertarik untuk melakukan penelitian dengan judul "Fenomena Bullying Antar Siswa di SMA Panca Bhakti Pontianak".

Masalahumum penelitian ini adalah "Bagaimana Fenomena Bullying Antar Siswa di SMA Panca Bhakti Pontianak?'Untuk memperjelas ruang lingkup penelitian, maka perlu diberikan batasan masalah kedalam sub-sub masalah, yakni :Apa saja bentuk-bentuk bullying antar siswa yang ada di SMA Panca Bhakti Pontianak? Apa saja faktor-faktor yang menyebabkan terjadinya bullying antar siswa di SMA Panca Bhakti Pontianak? Dan apa upaya pihak sekolah dalam mengatasi fenomena bullying antar siswa di SMA Panca Bhakti Pontianak?

\section{METODE PENELITIAN}

Penelitian ini menggunakan pendekatan kualitatif. Menurut Imam (2014: 80) penelitian dengan pendekatan kualitatif "menekankan analisis proses dari proses berpikir secara induktif yang berkaitan dengan dinamika hubungan antar fenomena yang diamati, dan senantiasa menggunakan logika ilmiah".Dengan demikian penelitian kualitatif bertujuan mengembangkan konsep sensitivitas pada masalah yang dihadapi, menerangkan realitas yang berkaitan dengan penelusuran teori dari bawah dan mengembangkan pemahaman akan satu atau lebih dari fenomena yang dihadapi.

Pengumpulan data dilakukan di SMA Panca Bhakti Pontianak serta dalam setting yang alamiah peneliti akan melakukan interaksi face to face sepanjang penelitian. Lokasi penelitian ini beralamat di Jalan. H.R. A. Rahman, Gg. Waspada 1, Kelurahan Sungai Jawi, Kecamatan Pontianak Kota, Kota Pontianak. Dalam penelitian ini, peneliti menggunakan dua bentuk sumber data, yakni sumber data primer dan sumber data skunder. Teknik pengumpulan data dengan cara wawancara dan studi dokumentasi. Alat pengumpul data dengan pedoman wawancara dan dokumentasi. Aktivitas dalam analisis data yaitu Data Reduction, data display, cloncusion drawing/verivitaction. Pengujian keabsahan data dengan perpanjangan pengamatan dan triangulasi.

\section{HASIL DAN PEMBAHASAN}

A. Hasil Penelitian

Setelah melaksanakan wawancara dan studi dokumentasi kepada Waka Kesiswaan, Guru BK dan Siswa SMA Panca Bhakti Pontianak, ditemukan bahwa bullying antar siswa yang ada di SMA Panca Bhakti Pontianak terdapat dua bentuk bullying yakni, bullying secara verbal seperti sorakan, memanggil nama siswa dengan nama orangtua nyasedangkan bullying fisik, antar siswa lebih kepada bentuk memukul, menghilangkan pulpen teman lain dan pemalakan.

Selain itu yang menjadi faktor penyebab bullying siswa di sekolah adalah faktor dari lingkungan keluarga, yang dimana pola asuh orangtua yang terlalu mengikat juga menjadi penyebab si anak melakukan tindak bullying yang dilakukannya di sekolah, selain itu pola asuh orangtua yang terlalu keras sehingga anak menjadi akrab dengan suasana yang mengancam, kurangnya kehangatan dan tingkat kepedulian orangtua yang rendah terhadap anaknya. Faktor selanjutnya adalah dari lingkungan teman sebaya. Siswa cenderung banyak menghabiskan waktu luangnya bersama teman-teman sebayanya baik di sekolah maupun luar sekolah, dengan berbagai sifat dan perilaku teman yang berbeda dapat menjadi pemicu si siswa ini untuk melakukan bullying. Sebagian besar di antara siswa yang melakukan bulllying, mereka ingin membuktikan, dianggap dan di akui bahwa si bully ini mempunyai kekuasaan atau status sosial yang lebih tinggi dari pada siswa lainnya. Kondisi lingkungan sosial dapat pula menjadi penyebab timbulnya perilaku bullying. Salah satu faktor lingkungan sosial yang menyebabkan timbulnya tindakan bullying adalah kemiskinan. Mereka yang hidup dalam kemiskinan akan berbuat apa saja demi memenuhi kebutuhan hidupnya. Sehingga tidak heran jika lingkungan sekolah sering terjadi pemalakan antar siswa.

Upaya yang dilakukan pihak SMA Panca Bhakti Pontianak dalam menanggulangi masalah bullying antar siswa adalah dengan cara mensosialisasikan tata tertib sekolah, hal ini dilakukan agar siswa tau apa yang harus dilakukan dan apa yang tidak boleh dilakukan saat berada dilingkungan sekolah. Selain itu dalam upaya pencegahan, SMA Panca Bhakti Pontianak mempunyai beberapa kegiatan pengembangan diri yang wajib diikuti oleh seluruh siswanya seperti voli, futsal, pramuka, paskibra. Dengan kegiatan-kegiatan tersebut siswa-siswa SMA Panca Bhakti Pontianak secara tidak langsung didoktrin untuk dapat saling menghargai satu sama lain antar siswa, dapat menerima perbedaan dan kekurangan di antara mereka dengan begitu dapat menekan angka terjadinya bullying atau mengurangi kasus bullying. Apabila bullying sedang terjadi, pihak sekolah langsung menegur siswa yang bersangkutan dan di berikan peringatan. Sedangkan bullying yang sudah terjadi, pihak SMA Panca Bhakti Pontianak menindak siswa yang bersangkutan untuk pemanggilan orang tua untuk dibina dan siswa tersebut wajib membuat surat perjanjian agar tidak melakukan bullying atau pelanggaran tersebut. 


\section{B. Pembahasan}

Berdasarkan hasil penelitian yang telah disajikan, maka pembahasan yang di bahas sesuai dengan urutan sub-sub masalah dalam penelitian ini yakni sebagai berikut :

1. Bentuk-bentuk bullying antar siswa di SMA Panca Bhakti Pontianak

Dengan pengumpulan data berupa wawancara dan studi dokumentasi kepada Waka Kesiswaan, Guru BK dan Siswa SMA Panca Bhakti Pontianak, peneliti menemukan bahwa bullying antar siswa SMA Panca Bhakti Pontianak terdapat dua bentuk, yakni bullying verbal dan fisik.Bullyingverbal antar siswa di SMA Panca Bhakti Pontianak berbentuk sorakan, hal tersebut timbul saat jam pembelajaran, ada siswa yang salah menjawab pertanyaan yang di berikan oleh guru mata pelajaran, maka secara spontan siswa lain menyoraki siswa yang salah menjawab pertanyaan dari guru tersebut.Menurutpengakuan Gibran selaku siswa kelas XII IPS SMA Panca Bhakti Pontianak hal tersebut sudah biasa terjadi tanpa ada maksud untuk menyakiti hati siswa tersebut, yang pasti apabila ada salah satu siswa yang salah dalam menjawab pertanyaan dari guru biasanya disoraki oleh teman-teman sekelas lainnya.

Hal tersebut dianggap biasa saja dan bukan menjadi atau menyebabkan suatu masalah yang besar. Tidak ada rasa amarah dari siswa yang tersoraki alias yang di bullying, begitu juga yang dilakukan oleh siswa lain yang menyoraki selaku si bully.Bentuk lainnya yang peneliti temukan adalah menyebut nama siswa lain dengan panggilan khusus. Kebanyakan siswa yang melakukan tindak bullying, mempunyai panggilan khusus terhadap korbannya, hal ini sejalan dengan apa yang telah dikatakan oleh yusuf selaku siswa kelas XI IPA SMA Panca Bhakti Pontianak, ia menuturkan bahwa ada saja siswa yang memanggil nama temannya dengan panggilan khusus.

Panggilan khusus tersebut biasanya berupa nama ayah yang terbully, bukan nama asli si siswa tersebut. Dalam hal itu, peneliti menemukan ada maksud dan tujuan lain mengapa si bully ini memanggil nama temannya dengan menyebut nama ayahnya, karena untuk mempermalukan si korban, agar siswa lainnya tahu nama orang tua si siswa yang terbullying ini. Fenomena ini sudah marak sekali terjadi pada jenjang sekolah dasar hingga ke jenjang yang lebih tinggi.

2. Faktor penyebab bullying antar siswa di SMA Panca Bhakti Pontianak

Dengan pengumpulan data berupa wawancara dan studi dokumentasi kepada Waka Kesiswaan, Guru BK dan Siswa SMA Panca Bhakti Pontianak, bahwa faktor utama penyebab siswa melakukan bullying adalah dari lingkungan pertama dimana siswa itu bersosialisasi, yakni lingkungan keluarga. Sisi pola asuh orang tua yang terlalu mengikat seperti tidak memperbolehkan anaknya untuk bermain dengan teman sebayanya, terlalu banyak aturan oleh orangtua kepada anaknya. Hal tersebut sudah pasti sangat tidak mengenakkan bagi si anak, dari pola asuh yang terlalu mengikat inilah menjadi pemicu anak untuk melakukan bullying di sekolahnya. Apabila dilihat dari sudut pandang dalam teori belajar menurut Albert Bandura (dalam
Sarwono, 2017: 28), perilaku orang tua tersebut akan di contoh oleh si anak. Seseorang belajar perilaku yang baru melalui observasi atau pengamatan kepada orang lain yang disebut "model". Lebih lanjut Bandura mengatakan bahwa, perilaku agresif merupakan sesuatu yang dipelajari dan bukannya perilaku yang dibawa individu sejak lahir perilaku agresif ini dipelajari dari lingkungan sosial seperti interaksi dengan keluarga.

Belum lagi pola asuh orangtua yang terlalu menyayangi anaknya, ini juga bisa menjadi bahan bullying di sekolah, bisa saja siswa lainnya mengejek siswa tersebut dengan membullyingnya dengan sebutan anak mami dan lain sebagainya. Situasidan kondisi di lingkungan keluarga yang brokenhome, apabila di suatu keluarga yang brokenhome sudah pasti anak yang menjadi korbannya, karena kurangnya perhatian dan pengawasan orangtua terhadap anaknya, apalagi dari sisi pemantauan perkembangan anak di sekolah. Anak korban brokenhome dapat melakukan bullying karena tidak ada didikan dari orangtua dirumah karena brokenhome tersebut.

Hal tersebut sejalan dengan hasil wawancara kepada waka kesiswaan yang menuturkan bahwa keluarga adalah tahap pertama didikan seorang anak, apabila di dalam lingkungan keluarga saja si anak tidak mendapatkan didikan yang baik, maka imbasnya si anak bisa melakukan bullying di sekolah, di sekolah, anak-anak yang terlibat dalam bullying akan di berikan bimbingan dan arahan bagaimana si siswa tersebut berperilaku sebagaimana mestinya, sesuai dengan norma dan nilai yang berlaku di suatu lingkungan. Perlunya kerjasama antar elemen seperti pihak sekolah dan orang tua, karena pendidikan dan mendidik tidak hanya datang dari sekolah, tetapi juga di semua pranata sosial, seperti salah satunya pranata keluarga.

Selain faktor lingkungan keluarga, lingkungan teman sebaya juga sangat mempengaruhi siswa untuk melakukan tindak bullying di sekolah. SMA Panca Bhakti Pontianak terdapat siswa yang heterogen, di antara mereka ada yang miskin, ada yang kaya, ada yang pintar, ada yang kurang pintar, ada yang patuh, dan ada juga yang menentang. Dengan karakter siswa yang berbeda-beda itulah maka peluang terjadinya bullying antar siswa semakin besar. Tidak ada yang bisa menjamin bahwa apabila sesama bully bergaul dan menjadi satu kesatuan kelompok dapat disiplin dan mentaati aturan yang berlaku di sekolah.

Menurut (Usman, 2013), kelompok teman sebaya (genk) yang memiliki masalah di sekolah akan memberikan dampak yang buruk bagi teman-teman lainnya seperti berperilaku dan berkata kasar terhadap guru atau sesama teman dan membolos. Anak-anak ketika berinteraksi dalam sekolah dan dengan teman di sekitar rumah, kadang kala terdorong untuk melakukan bullying. Beberapa anak melakukan bullying hanya untuk membuktikan kepada teman sebayanya agar diterima dalam kelompok tersebut, walaupun sebenarnya mereka tidak nyaman melakukan hal tersebut. 
Kondisi lingkungan sosial dapat pula menjadi penyebab timbulnya perilaku bullying. Salah satu faktor lingkungan sosial yang menyebabkan timbulnya tindakan bullying adalah kemiskinan. Mereka yang hidup dalam kemiskinan akan berbuat apa saja demi memenuhi kebutuhan hidupnya. Sehingga tidak heran jika lingkungan sekolah sering terjadi pemalakan antar siswa.

3. Upaya SMA Panca Bhakti Pontianak dalam menanggulangi masalah bullying antar siswa

Dengan pengumpulan data berupa wawancara dan studi dokumentasi kepada Waka Kesiswaan, Guru BK dan Siswa SMA Panca Bhakti Pontianak, peneliti menemukan bahwa upaya SMA Panca Bhakti Pontianak dalam menanggulangi masalah bullying antar siswa adalah dengan caratindakan preventif, represif dan kuratif.Usaha Preventif dengan mengadakan kegiatan pengembangan diri siswa dan sosialisasi tata tertib.

Sosialisasi tata tertib perlu dilakukan agar nilai dan norma yang ada ataupun yang telah tercipta di SMA Panca Bhakti Pontianak dapat dilestarikan dengan sebagaimana mestinya. Pembentukan seperangkat peraturan ini akan membantu semua pihak supaya mereka memiliki pemahaman yang sama mengenai apa yang dapat dilakukan dan apa yang tidak dapat dilakukan terkait dengan bullying.

Selain itu untuk mencegah terjadinya bullying, SMA Panca Bhakti Pontianak mengagendakan pengembangan diri yang wajib untuk diikuti oleh para siswa-siswanya. Kegiatan ini berupa olahraga voli, futsal, pramuka, paskibra. Kegiatan-kegiatan ini diadakan untuk mempersatukan seluruh siswa dari kelas X hingga kelas XII agar dapat membaur menjadi satu. Setiap siswa dibebaskan untuk memilih aktivitas pengembangan diri apa yang ingin diikutinya.Dalam implementasinya, kegiatan ini mencerminkan nilai-nilai kebersamaan, saling menghargai, kekompakkan dan bentuk-bentuk persatuan lainnya. Dengan begitu, akan meminimalisir tindak bullying antar siswa di kemudian hari. Kegiatan pengembangan diri ini dilakukan rutin setiap seminggu sekali. Secara teoritis, karakter dan moral anak akan terdidik melalui kegiatan ini, maksudnya pendidikan berusaha untuk mengembangkan pola perilaku seseorang sesuai dengan kehendak atau masyarakatnya. Kehendak ini berwujud moralitasatau kesusilaan yang berisi nilai-nilai kehidupan nyata, (Adisusilo, 2011: 70).

Sedangkan tindak Represif yang dilakukan oleh pihak SMA Panca Bhakti Pontianak adalah dengan cara memberikan teguran secara langsung kepada si bully. Untuk hal ini, menurut Pak Supeno selaku waka kesiswaan, semua elemen termasuk kepala sekolah, staf tata usaha dan para guru serta satpam berhak untuk memberikan teguran kepada siswa yang tertangkap basah atau melakukan tindak bullying. Keterlibatan dan peran aktif dari semua pihak akan semakin memperkuat tercapainya lingkungan yang bebas bullying. Kebijakan yang terintegrasi akan lebih terasa efeknya bila SMA Panca Bhakti Pontianak mampu membentuk sebuah tim kerja yang terdiri dari semua unsur sekolah lengkap dengan peranannya masing-masing.
Terdapatpengurangan point sesuai jenis pelanggarannya. Bagi siswa yang telah mencapai poin pelanggaran, maka konsekuensinya adalah sebagai berikut : point pelanggaran mencapai 15 , dilakukan peneguran secara lisan dan membuat pernyataan untuk memperbaiki diri. Semua komponen yang ada di sekolah baik itu Kepala Sekolah, Guru-guru serta Staf Tata Usaha maupun Satpam mempunyai peran penting dalam menanggulangi atau mencegah tindakan bullying di sekolah. Oleh sebab itu, Pihak SMA Panca Bhakti Pontianak perlu menangani secara komprehensif dan sistematis untuk mencegah dan mengentaskan tindakan bullying di sekolah.

Sesuai peraturan yang ada, pengambilan tindak Kuratif jugadilakukan sesuaidengan jenis pelanggaran yang telah dilakukan siswa. Seperti yang telah tertera dalam tata tertib yang berlaku. Bullying dengan melakukan tindak asusila akan di kurangi point 100 sanksi yang di dapatkan adalah Dicatat dan pengurangan point. Siswa dikembalikan kepada orang tua. selain itu Mengambil paksa barang milik teman (merampas). Point berkurang 25, sanksinya Peringatan dan membuat perjanjian.Dengan hal ini SMA Panca Bhakti Pontianak secara langsung memberikan memberikan penyadaran kepada para pelaku penyimpangan agar dapat menyadari kesalahannya dan mau memperbaiki kehidupannya, sehingga di kemudian hari tidak lagi mengulagi kesalahannya.Selaras dengan hal tersebut, menurut Anto (2010: 17) untuk mengembalikan keadaan seperti semula, perlu dilakukan usaha pemulihan, oleh sebab itu kuratif ini bertujuan agar si pelaku bullying dapat kembali mematuhi aturan dan norma yang berlaku.

Dan jika bullyingnya Merusak / menghilangkan harta benda milik teman. Point akan berkurang 25, sanksinya Peringatan dan pembinaan oleh wali kelas dan guru BK, mengganti barang yang hilang.

\section{A. Kesimpulan}

\section{PENUTUP}

Hasil penelitian menunjukkan bahwa bentuk bullying yang dominan terjadi adalah bullying fisik dan bullying verbal. Faktor penyebab yang paling dominan adalah faktor keluarga, teman sebaya dan lingkungan sosial.Diikuti dengan usaha SMA Panca Bhakti Pontianak dalam menanggulangi masalah bullying antar siswa dengan menerapkan pengendalian sosial berupa preventif, represif, dan kuratif.

\section{B. Saran}

SMA Panca Bhakti harus lebih banyak untuk mengadakan pertemuan atau tatap muka kepada komite sekolah, termasuk didalamnya pengawas pendidikan untuk memantau keberhasilan siswa dalam menuntut ilmu di sekolah agar tidak melakukan tindak bullying yang sedang marak belakangan ini. Selain itu sekolah harus punya program sekolah yang damai atau yang biasa dikenal dengan sebuta, Peaceful School.Peaceful school merupakan upaya untuk menyiapkan generasi yang cerdas nalar, cerdas emosional dan cerdas spiritual. Mengingat peaceful schoolini merupakan sekolah yang damai yaitu sekolah 
yang kondusif bagi proses belajar mengajar yang memberikan suasana aman, nyaman dan tentram pada setiap komponen di sekolah karena adanya kasih sayang, perhatian, kepercayaan dan kebersamaan. Didalam peaceful school terdapat aspek-aspek yang harus diperhatikan, yaitu penghargaan terhadap kehidupan, anti kekerasan, berbagi dengan yang lain, mendengar untuk memahami, kekompakkan, kerjasama, kesetaraan gender.

\section{DAFTAR PUSTAKA}

Anto, Juli. 2010. Pengendalian Sebagai Upaya Mencegah Penyelewengan Norma di Masyarakat. Jakarta Timur: CV Rama Edukasitama

Indrawan, A. F. 2017. KPAI Terima Aduan 26 Ribu Kasus Bully Selama 2011-2017. https://news.detik.com/berita/d-367007\9/kpaiterima-aduan-26-ribu-kasusbully-selama-20112017Diakses pada Tanggal 22 Januari 2019.

Priyatna, A. 2010. Let's End Bullying Memahami, Mencegah, Mengatasi Bullying. Jakarta: PT. Elex Media Komputindo.

Prasetyo, Ahmad Baliyo Eko, 2011. _Bullying Di Sekolah Dan Dampaknya Bagi Masa Depan Anak, Jurnal Pendidikan Islam El-Tarbawi, IV.

Saputra, E. 2017. Kemensos: Bullying Harus Diselesaikan dengan Secara Mendidik. https://www.merdeka.com/pendidikan/kemensosbullying-harus-diselesaikandengan-secaramendidik.htmlDiakses pada Tanggal 22 Januari 2019.

Sarwono, Sarlito.W. 2017. Teori-teori Psikologi Sosial. Depok: PT. Rajagrafindo Persada

Suharsaputra, Uhar. 2012. Metode Penelitian Kuantitatif, Kualitatif, dan Tindakan. Bandung: PT. Refika Aditama

Sutarjo, Adisusilo. 2011. Pembelajaran Nilai Karakter. Jakarta: Rajawali Pers.

Usman, Irvan. 2013. Kepribadian, Komunikasi, Kelompok Teman Sebaya, Iklim Sekolah dan Perilaku Bullying, Humanitas Vol. X No. 1.

Wiyani, N. A. 2014. Save Our Children From School Bullying. Djogjakarta: Ar-Ruzz Media. 